\title{
Os Desafios do Estágio Supervisionado em um Curso de Licenciatura a Distância
} The Challenges of the Supervised Internship in a Distance Bachelor's Degree Course

\section{Layla Júlia Gomes Mattos*}

Silvana Claudia dos Santos

Universidade Federal de Viçosa. Avenida Peter Henry Rolfs, s/n Campus Universitário - Viçosa, MG - Brasil.

laylajgmattos@gmail.com

\section{Resumo}

Este trabalho teve por objetivo investigar como acontece o estágio supervisionado em uma licenciatura ofertada a distância. Para tanto, o nosso olhar buscou compreender como os estágios supervisionados do curso de licenciatura em Matemática a distância de uma universidade federal mineira têm sido propostos pela instituição, como eles são organizados pelo professor responsável pelas disciplinas de estágio e como eles são vivenciados pelos alunos. Essa pesquisa é de cunho qualitativo e se constituiu na análise de dados de documentos oficiais da universidade, de entrevistas online com a professora orientadora dos estágios e com estagiários e de relatórios de estágios elaborados por alunos do curso. Concluímos que os princípios da racionalidade técnica, pautados na lógica três (teoria) mais um (prática), é ainda dominante. Acreditamos também que um dos principais problemas que a EaD tem vivenciado é justamente o fato de se estar reproduzindo o modelo presencial, partindo da cultura "presencialista", e elaborando adaptações para o uso de AVA e suas ferramentas, sendo essa uma das dificuldades enfrentadas pelos docentes que atuam na modalidade.

Palavras-chave: Educação Matemática,Educação a Distância, Formação inicial de professores,Teoria e prática, Licenciatura em Matemática. 


\title{
The Challenges of the Supervised Internship in a Distance Bachelor's Degree Course
}

\begin{abstract}
The objective of this paper was to investigate how the supervised internship takes place in a degree offered at distance. In order to do so, our view sought to understand how the supervised internships of the degree course in Mathematics at distance of a Federal University in Minas Gerais have been proposed by the institution, how they are organized by the professor responsible for the internship subjects and how they are experienced by the students. This research is qualitative and was based on the analysis of data in official documents of the University, of online interviews with the internship teacher and with the trainees, as well as of reports of internships elaborated by students of the course. We conclude that the principles of technical rationality, based on logic three (theory) plus one (practice), is still dominant. We also believe that one of the main problems that the EaD has experienced is precisely the fact of reproducing the face-to-face model, starting from the "face-to-face" culture, and elaborating adaptations for the use of AVA and its tools, that being one of the difficulties faced by teachers who work in the modality.I
\end{abstract}

Keywords: Mathematical Education, Distance Education, Initial teacher training, Theory and practice, Degree in Mathematics.

\section{Introdução}

O estágio é o elemento central da discussão desenvolvida neste artigo. Entendemos que, em cada contexto formativo onde é vivenciado, ele pode assumir características diferentes. Assim, procuramos direcionar o nosso olhar para como o estágio acontece no contexto de formação de professores e, mais especificamente, no âmbito da Educação a Distância (EaD).

Pesquisas como as de Quaranta (2011), Reis (2015) e Álvares (2015) sobre estágio na EaD apontam para indícios de que, no contexto da modalidade, ele vem sendo organizado pelas instituições de ensino superior sob os moldes do ensino presencial. Nossa pesquisa, por sua vez, procurou investigar de forma mais aprofundada essa realidade; para tanto, buscamos analisar como acontece o estágio supervisionado a distância, com ênfase em evidenciar como ele é proposto pela instituição de ensino, como é organizado pelo professor orientador e como é praticado pelos estagiários.

Para tal, investimos em compreender como é desenvolvido o estágio supervisionado no curso de Licenciatura em Matemática à distância da Universidade Federal de Viçosa (UFV). O curso teve início no primeiro semestre de 2011; suas vagas foram destinadas a professores da Educação Básica que não tinham formação superior, com intuito de atender às demandas do Plano Nacional de Formação de Professores da Educação Básica (Parfor) 1 . As vagas que não foram preenchidas por alunos provenientes dessa demanda foram ofertadas a candidatos caracterizados por demanda social.

Acreditamos que, por meio dessa análise, podemos contribuir com as discussões teóricas a respeito do estágio, da EaD e das licenciaturas de modo geral, uma vez que a estrutura dos cursos de licenciatura a distância tem sido pauta de pesquisas, tais como as de Gatti (2010; 2013-2014) e Barreto (2015) e vem sendo debatida em diversos aspectos no campo da Educação. Esperamos, então, que investir em pesquisas

1 Mais informações sobre o Parfor podem ser obtidas no portal do Ministério da Educação e Cultura (MEC): www.portal. mec.gov.br. 
que apresentem as diferentes vozes desse contexto possa colaborar, por exemplo, para uma revisão da organização dos cursos e da legislação que define os parâmetros para elaboração de cursos ofertados na EaD.

\section{Caminhos Metodológicos}

Para atender à proposta de investigação do estágio no contexto do referido curso, optamos pelo paradigma qualitativo de pesquisa, visto que queríamos chegar ao "como acontece", pergunta para qual não apresentaremos respostas definitivas, mas sim reflexões que podem colaborar com as discussões sobre a EaD e suas especificidades.

Acreditamos que a abordagem que escolhemos é marcada pela transitoriedade dos dados produzidos, pela ausência de neutralidade do pesquisador e pela possibilidade de reconfiguração dos dados diante da oportunidade de mudança de compreensão e produção dos dados. Além disso, a pesquisa qualitativa é marcada pelo não estabelecimento de caminhos prévios rígidos e generalistas para o seu desenvolvimento (Garnica, 2006).

Para efeito de produção de dados, o trabalho foi dividido em quatro partes: análise de documentos e regimentos sobre estágio da UFV; análise dos relatórios de estágio produzidos pelos alunos; entrevista com a professora orientadora do estágio; e entrevista com alunos selecionados a partir da leitura de 21 relatórios deles, cedidos pela professora orientadora.

Após o tratamento dos dados dos relatórios e documentos oficiais, realizamos a entrevista com a professora orientadora da disciplina de estágio e, posteriormente, com duas alunas do curso, selecionadas a partir dos relatórios. Optamos pela entrevista semiestruturada; com o objetivo de tornar a pesquisa exequível em tempo hábil, achamos mais adequado realizá-las online, via chat em uma rede social, pois os alunos estavam espalhados por várias cidades e não seria viável, com os recursos disponíveis, encontrá-los pessoalmente.

A opção pelo chat se deu pela conveniência apontada por Borba, Malheiros e Amaral (2011) de as entrevistas poderem ser mais tarde transformadas em arquivos de texto, estando originalmente transcritas. A partir daí nos dedicamos à descrição dos dados.

Para a análise dos dados, investimos num diálogo constante com o referencial teórico, procurando encontrar características próprias do estágio no contexto da EaD. Nossas análises finais buscaram compreender, principalmente, o lugar do estágio no planejamento institucional, o desenvolvimento da orientação e da supervisão do estágio e, por fim, a narrativa sobre os estágios nas escolas, evidenciando, assim, como ele acontece no contexto de um curso de licenciatura a distância.

\section{O Estágio Supervisionado nas Licenciaturas Ofertadas a Distância}

Na formação acadêmica, o estágio tem sido o principal responsável por trazer a experiência da sala de aula e da escola para vida do futuro professor. Lüdke (2013, p.123), estudando a realidade do estagiário e discutindo o papel do estágio na formação do professor, afirma que a "formação oferecida pelos cursos de licenciatura não está correspondendo ao que é necessário para o desempenho do trabalho docente". A exemplo disso, ela alega que o estágio está no centro dos problemas que as instituições formadoras têm vivenciado para articular teoria e prática na grade curricular de seus cursos. Em concordância com essa ideia, Gatti (2013-2014) sustenta que a pesquisa sobre formação de professores tem evidenciado uma "insuficiência formativa" nas licenciaturas, voltadas para o desenvolvimento do trabalho docente. $\mathrm{E}$ acrescenta a isso as condições em que os estágios são realizados. Gatti (2013-2014) afirma que, embora seja difícil analisar os dados que procedem do estágio, é possível observar por meio desses estudos que a maioria dos estágios conta com a observação como principal forma de inserção. Além disso, ela 
explica que os estudantes costumam procurar eles próprios as escolas onde irão estagiar, sem contar com a devida supervisão e articulação entre a instituição de ensino superior e as que os recebem nesse período, corroborando o que Pimenta e Lima (2005-2006) ressaltam sobre a falta de importância dada a quem e a como é coordenado o período do estágio.

Essa falta de comprometimento com a gestão do estágio e com o papel que ele deveria exercer na formação do futuro professor acaba deixando brechas para que seja um "substantivo fictício" (Lüdke, 2014). Isso é devido a diversos aspectos que implicam a falta de inserção efetiva do estagiário no contexto escolar, como: professores regentes assinam cadernos de presença sem que o aluno tenha frequentado o estágio, o professor regente poucas vezes se vê como peça fundamental nesse processo de formação; e estagiários se sentem meros observadores, ao invés de assumirem postura ativa no seu processo de formação.

Em contrapartida a esse tipo de prática, o estágio, se visto como elemento articulador entre o curso e a dimensão da prática docente, contará com a característica da mobilidade e de trânsito entre os espaços da universidade e da escola, das suas concepções, desafios e ideias, por exemplo(Felício; Oliveira, 2008). Para Felício e Oliveira(2008,p. 217),isso pode favorecer a "construção significativa de aprendizagens" não só para os estagiários como também para o professor regente e o professor orientador.

Segundo Barreto (2015), as fragilidades dos cursos de licenciatura podem ser atribuídas às condições recentes de sua expansão, isto é, grande crescimento das matrículas a distância e por meio das instituições de ensino superior (IES) privadas. Para ela, isso é preocupante, pois, por terem interesse de mercado, essas instituições não realizam pesquisas e não se empenham nas atividades do ensino. Outro ponto abordado é que, com o rápido crescimento da Educação a Distância, houve improvisação do projeto pedagógico, da infraestrutura de apoio e acompanhamento dos estudantes e uma grande evasão, o que deixa indícios de que ela pode oferecer uma formação ainda mais precária que a presencial.

Para Gatti (2013-2014), a EaD não favorece o convívio de seus estudantes com a cultura acadêmica do diálogo direto com as pessoas envolvidas no processo de formação, como movimentos estudantis, entre outras vivências características da modalidade presencial. Ela afirma, categoricamente, que a EaD vem sendo oferecida de maneira mais precária que a presencial e que, ao invés de contribuir para melhorias nacrise existente na formação inicial, pode torná-la mais frágil.

Borba, Malheiros e Amaral (2011), olhando para possibilidades e reconhecendo a palavra "distância" como termo essencial para a $\mathrm{EaD}$, veem as relações estabelecidas na modalidade, mediadas pela tecnologia, com mais otimismo, considerando-a como uma oportunidade de reunir pessoas geograficamente distantes, abrindo espaço para uma possível troca entre culturas diferentes. Os autores ressaltam que, independente da proposta utilizada, será necessário o uso de meios tecnológicos para tornar viável a comunicação. Esses espaços são conhecidos como ambientes virtuais de aprendizagem (AVA); dependendo dos recursos de que dispõem, podem favorecer experiências de ensino e aprendizagem qualitativamente diferentes - por exemplo, se contam com recursos de áudio e vídeo ou apenas chats. Por esse motivo, o currículo deve ser pensado de acordo com as possibilidades das mídias disponíveis.

No que tange ao estágio, que é um dilema da formação de professores, como apresentado anteriormente, autores como Quaranta (2011), Reis (2015) e Álvares (2015),em diferentes pesquisas, indicam uma defasagem na organização da $\mathrm{EaD}$ que vem negligenciando principalmente a distribuição de papéis e a utilização de recursos sem reconhecer características específicas da modalidade. A reprodução do ensino presencial é um dos pontos mais contraditórios abordados pelos autores e aponta para uma necessária elaboração de fundamentos característicos para a modalidade cuja "distância" é elemento básico de sua concepção. Assim, analisamos que é preciso refletir sobre essa "customização" do ensino presencial, que vem gerando a formação precária para repensarmos a EaD da cultura "presencialista" para a possível cultura "distancialista". 
Nas Diretrizes Curriculares Nacionais (DCN) voltadas para a normatização dos cursos na modalidade a distância, o estágio é citado uma única vez no Art. $1^{\circ}, \S 1^{\circ}$ do Decreto $n^{\circ} 5.622$, de 2005 . Nesse artigo afirma-se que os estágios "serão realizados na sede da instituição ou nos polos de EaD credenciados, admitindo-se convênios para a realização dos estágios supervisionados, em conformidade com a legislação vigente" (Brasil, 2016). Esse aspecto evidencia que não se admite, ao menos no papel, que essa fase da formação pode ser marcada pelas especificidades da EaD.

Tendo em vista que, se na modalidade presencial o estágio é um nó, na modalidade a distância, ainda carente de pesquisas e políticas, ele tende a ganhar características que agregam ainda mais dificuldades ao processo vivenciado pelo estagiário, tais como as apontadas por Barreto (2015): alunos com dificuldade de conciliar estágio, graduação e trabalho; professores sem formação para trabalhar na EaD e/ou pouco comprometidos com as demandas da disciplina de estágio; tutores sendo o único suporte-supervisor-orientador do aluno; pouca exploração das mídias disponíveis etc.

Olhando por esse ângulo, mesmo que toda a legislação e toda a organização do estágio na modalidade a distância sejam copiadas da modalidade presencial, ainda assim ele será diferente, particular, constituído de especificidades. O futuro professor é exposto a modelos de aulas e de professores durante toda a formação escolar e acadêmica, por exemplo. Mas, o aluno da modalidade a distância tem a oportunidade de vivenciar um espaço de mediações que não são convencionais, ainda que apresentem muitas semelhanças com o presencial.

\section{Desafios do Estágio Supervisionado no Contexto de um Curso de Licenciatura em Matemática a Distância}

Em nossa análise, emergiram diversos temas, dos quais destacamos: o lugar que o estágio ocupa no planejamento institucional; como se deu o desenvolvimento da orientação e da supervisão; e a narrativa dos estagiários sobre as experiências nas escolas.

De modo geral, observamos que a instituição, o professor regente e o professor orientador compreendem pouco o seu próprio papel no estágio e, no que se refere à sua organização, se moldam ao ensino presencial sem considerar as especificidades da EaD, corroborando as pesquisas sobre estágio na modalidade a distância já apresentadas. Essa postura aponta para uma despreocupação com o estágio em si e não apenas com o modo como ele acontece sendo supervisionado e orientado a distância.

A partir de nossos dados, observamos também que não há definições para os estágios supervisionados a distância nos documentos oficiais da graduação na UFV, mas sim documentos elaborados para o curso em questão, evidenciando uma separação entre a modalidade presencial e a modalidade a distância. O regimento determina, em seu Art. 3o, que "os conteúdos curriculares do curso [...] são sistematizados numa matriz curricular que indica a integração horizontal e vertical das disciplinas e atividades" (UFV, 2015, p.2), indicando que ele não deve ser organizado como culminância dos cursos.

Os estágios são elaborados como disciplinas pedagógicas, mas não estabelecem relação com as disciplinas que compreendem esse grupo, tampouco com as demais disciplinas do curso, ainda que os documentos indiquem que elas devam ser integradas na grade curricular de forma horizontal e vertical. Segundo o documento, os estágios também compõem o grupo de orientação acadêmica, no qual se encontram as disciplinas de monografia, projetos, trabalhos de conclusão de curso (TCC) e atividades complementares. Apesar de estarem no mesmo grupo, compreendemos que cada uma dessas disciplinas demandam caminhos e estratégias distintas de orientação, visto que os processos e os resultados que são produzidospor elas geralmente são diferentes. Ainda assim, não há distinção entre elas no regimento, tampouco para o papel do orientador de cada uma delas, o que nos impede de compreender claramente o que se espera 
desse processo de orientação. Além disso, na grade curricular do curso em estudo, constatamos a oferta de três estágios supervisionados apresentados ao aluno nos três últimos semestres, indo na contramão do que discutimos anteriormente e das diretrizes que o próprio regimento institucional propõe.

Historicamente, cursos de graduação organizam as disciplinas no formato 3+1, baseado no modelo da racionalidade técnica (Diniz-Pereira, 1999). Nesse modelo a teoria é apresentada nos primeiros três anos e depois explorada em um ano de prática. No caso das licenciaturas, esse ano de finalização é geralmente composto por disciplinas pedagógicas; entre elas se encontra o estágio e boa parte das disciplinas de orientação citadas anteriormente, vistas como peças de acabamento do processo de formação, como discutimos anteriormente. Segundo Dias-da-Silva et al. (2008, p.20),

formar professores pressupõe a criação e a implementação de um projeto específico e partilhado por todos os docentes da universidade, que precisam superar a ruptura bacharelado \& licenciatura: tanto os "professores das pedagógicas" quanto os "professores de conteúdo" (!) formam professores...

Diante disso, pensamos que há dificuldade em promover essa articulação com outras disciplinas nas grades curriculares de graduação e, entre a diversidade de motivos que possam impedir essas mudanças, um deles, por exemplo, seria o fato de ela demandar um investimento em elaboração de novas propostas de organização dos estágios. Isso exigiria um trabalho de constante diálogo entre professores coordenadores de estágio e os demais professores dos cursos de formação, quebrando a ideia de que os alunos das licenciaturas se tornam professores somente a partir do encontro com conceitos e experiências apresentadas nas disciplinas pedagógicas. Afinal, todos os professores de um curso de licenciatura estão diretamente ligados à formação do futuro professor.

Concordamos com Dias-da-Silva et al. (2008, p.20) que construir novos projetos de trabalho,

nesses tempos sombrios de fragilização da universidade pública, implica, além da dificuldade em construir consensos possíveis dentro da própria área de Educação, também a necessidade de enfrentarmos os entraves institucionais e administrativos do cotidiano universitário.

Além disso, essa desconstrução de modelos, além de trabalhosa, exigiria mudanças de concepção, tais como: “O que é estágio?"; “Para que ele serve?"; e "Qual é o papel dos atores envolvidos?". As escolas, por exemplo, precisariam ser apresentadas ao estágio e incluídas no processo, não só como recepcionistas dos alunos ou como quem cede espaço a eles, mas como participantes ativas e corresponsáveis pela formação do profissional docente, como já debatemos. Para Santos (2005), no entanto, promover essa parceria com os profissionais das escolas não é simples, sendo, na verdade, uma conjuntura delicada e conflituosa, uma vez que, nos estágios, a relação entre professores e estagiários não tem sido vista por eles como um espaço de produção do conhecimento de forma complementar e interdependente entre os sujeitos envolvidos.

Ao contrário disso, a autora afirma que

essa relação ainda é marcada por inúmeras situações constrangedoras em que o estagiário é visto como aquele que está para "julgar" uma prática pedagógica profissional alheia. Sobretudo porque a escola, principalmente a pública, apresenta-se tão vulnerável, fragilizada, insegura, que qualquer aproximação externa pode desencadear situações "mal entendidas" (Santos, 2005, p.4). 
No projeto pedagógico (PP) do curso investigadoas especificações para o estágio evidenciam indícios de que essa relação de aproximação com as escolas deva acontecer. Todavia, ela está amparada pela atuação de um único sujeito, o professor orientador do estágio. Tal sujeito, na licenciatura analisada, foi uma tutora remanejada para a função de professora orientadora das disciplinas de estágio. Segundo o $\mathrm{PP}$, em síntese, seu trabalho compreendia, além de garantir que o termo de compromisso fosse respeitado e que todas as partes tivessem ciência do que lhes competia, orientar, acompanhar, supervisionar e avaliar os alunos, estabelecendo parceria com o professor ou supervisor de estágio nos espaços formais do campo. Ao mesmo tempo, deveria selecionar, contatar e visitar os locais de estágio antes e durante o estágio. No entanto, o documento não garante condições, em se tratando de um curso a distância, para que o professor orientador desempenhe essas funções, tais como transporte e estadia, por exemplo. Segundo a docente,

gostaria de ter ido às escolas, encontrado com os professores que receberam esses alunos, mas só consegui fazer isso no último estágio e somente em dois polos, pois não teve transporte (Professora orientadora).

No curso analisado, o estágio se resume a um protocolo realizado ao final das aulas teóricas; a falta de comprometimento com o processo de orientação indica possivelmente negligência da instituição com o modo como os estágios seriam orientados e com a sobrecarga de trabalho da profissional que designaram para a função. A tutoria sendo explorada para "tapar buracos" da organização é uma particularidade recorrente na EaD; no caso em questão, "tapa um buraco" muito importante da formação do licenciando, que é o estágio, e não favorece o processo, visto que o tutor não foi formado e pago para desempenhar as funções de professor, incluindo a de orientador.

Para além do desvio de função, a supervisão a distância é uma singularidade do curso em questão e precisa ser reelaborada para que o professor orientador consiga cumprir as funções atribuídas a ele. A orientação se deu sempre por meio de e-mail e chat. Esse aspecto marca uso pouco exploratório das tecnologias digitais disponíveis, essenciais para a modalidade. Os alunos acabaram vivenciando o processo de estágio por meio de um diálogo frágil com a orientação, e, por consequência, sem nenhuma comunicação entre o que a UFV propõe para seus alunos e os sujeitos que estiveram diretamente ligados ao processo de formação deles. Essa distância posta entre as partes não é necessariamente de ordem geográfica, mas corrobora o que a literatura que discutimos aponta em diversos momentos: não há um vínculo de parceria entre as instituições envolvidas. Há uma ponte, improvisada, feita pelos estagiários, que serve de exclusiva ligação entre o que se propõe, organiza e orienta e o que se vivencia no estágio supervisionado a distância que investigamos.

A experiência dos estagiários se baseou em uma atuação norteada pela tríade observação-participação-regência:

As disciplinas são dividas numa parte teórica e outra prática. Como foram três estágios, dividi assim:a parte teórica foi feita a distância com textos e vídeos buscando relacionar com a prática (Professora orientadora).

O material de orientação foi disponibilizado no AVA da instituição - PVANET -, evidenciando a organização das três disciplinas de estágio e a carga horária determinada destinada a cada momento de inserção do aluno na escola. No mais, segundo ela, "As orientações eram feitas via slides e e-mail". 
Como resultado do estágio, são apresentados relatórios elaborados pelos alunos no término de cada período estagiado; este é o principal item de apreciação da sua experiência formativa pelo professor orientador. Esses relatos poderiam assegurar melhor aproveitamento do aprendizado, se não fossem vistos apenas como instrumento de avaliação (Lüdke, 2013). Sobre esse aspecto, a autora argumenta que a mais importante contribuição desse tipo de avaliação é fornecer elementos para a melhoria do processo de formação, o que poderia acontecer se o relatório fosse analisado antes de concluir esse processo.

Além disso, acreditamos, há um "desperdício" de informações que são preenchidas nos relatórios sobre a escola e seus sujeitos, por exemplo, e que não são posteriormente discutidas com os estagiários.

Em diversos casos, os estagiários relatam que se sentiram inseguros no processo de inserção na escola: alguns nos primeiros dias de observação, diante do estranhamento da turma; outros na regência, diante da indisciplina dos alunos e do trabalho de esboçar e executar um plano de aula. Entendemos que essa instabilidade seja natural para o movimento que o estágio agrega à formação inicial, mas cremos que essas questões precisam ser discutidas, elaborando e refletindo com os alunos quanto à concepção de que a sua formação não contemplará todos os adventos que a escola pode apresentar a ele no decorrer do exercício da profissão. Sendo assim, é preciso que eles compreendam o estágio como um processo que abre caminhos - e não que conclui etapas. Rela (2006) vê esse momento da formação como um momento de síntese. Nós, porém, não concordamos com essa perspectiva, pois poderíamos interpretar o estágio como uma espécie de resumo de algo pronto - no caso, a formação inicial. Entretanto, acreditamos, e estamos debatendo desde o início, que o estágio é um espaço de produção conjunta de todas as partes envolvidas no processo, e não de aplicação. Não o consideramos uma página em branco em que o ponto de partida é inovador; parte-se, obviamente, de uma realidade em movimento. Contudo, também não é um livro pronto, visto que o estagiário, ao entrar na escola, muda o ritmo e os caminhos que estão sendo vividos. Assim, o final do processo é um caminho diverso em possibilidades.

O estágio, em qualquer modalidade de ensino, precisa fazer parte de uma formação que estará em constante desenvolvimento, buscando refletir sobre as vivências da docência e até mesmo superar questões como as dificuldades - como a indisciplina dos alunos -, quando possível, e a insegurança dos novatos ou nem tanto na profissão docente. Assim, partimos da concepção de que "o conceito de 'desenvolvimento' tem uma conotação de evolução e continuidade que, em nosso entender, supera a tradicional justaposição entre formação inicial e formação contínua dos professores" (Marcelo, 2009, p. 9).

Em geral, os estagiários avaliaram o estágio como uma experiência importante para sua formação e que contribuiu para seu exercício da docência, tanto na fala de quem já havia lecionado ou já lecionava quanto na fala de alunos cujo primeiro contato com o exercício docente foi por meio do estágio.

Alguns alunos reforçam a necessidade de os professores desenvolverem atividades diversificadas, saindo, segundo eles, do modelo de aulas tradicionais cujo uso do "quadro e giz" e a aula expositiva são frequentes, em busca de aulas mais dinâmicas que explorem atividades lúdicas e em grupo, por exemplo. Essa fala geralmente vem acompanhada da participação dos alunos nas atividades de regência e é sempre avaliada como algo gratificante e motivador para desenvolverem outras atividades semelhantes. Como exemplo disso, uma aluna relata a expectativa de que a regente dê continuidade ao trabalho que ela desenvolveu no estágio, avaliando que o uso de material manipulável torna a aula dinâmica e criativa, considerando como desvantagem, no entanto, que esse tipo de aula demandará do professor mais tempo para planejar, saindo da rotina do uso do quadro e do livro.

A relação dos estagiários com a orientadora se restringiu, em sua maior parte, à supervisão do cumprimento de normas que garantem que o aluno foi à escola e fez o estágio,como se o "fazer", no sentido das experiências proporcionadas por esse momento da formação, já estivesse pronto e à espera do estagiário. Este, por sua vez, precisa tão somente experimentar a realidade da escola e aprender como se faz. Sob 
essa perspectiva, os estágios são de fato supervisionados e concluídos como determinam os regimentos. No entanto, a orientação por parte dos professores orientador e regente praticamente não se efetiva.

Diante disso, concluímos o que o estágio, entendido como a prática, carece de contínua reflexão; não só no contexto acadêmico de formação como também no contexto da escola. O professor regente que não se vê como coautor do estágio, o estagiário mero observador e o professor orientador atuando como supervisor e avaliador final não conferem a esse momento da formação o que ele realmente deveria ser. Isso não é responsabilidade propriamente deles, entendemos. Todavia, é consequência de uma concepção de estágio que tem sido construída, alargada, redefinida e, principalmente, questionada historicamente e ainda carece de reflexões.

\section{Considerações Finais}

O estágio consiste em um dos nós da formação de professores, como aponta a literatura, e no âmbito da EaD ele se torna um desafio ainda maior. Na fala dos autores que estudamos e na análise dos dados de nossa pesquisa, identificamos o estágio como marcado pela concepção de que, inicialmente, o aluno se apropria da teoria e, no final do curso, vivencia, como estagiário, a prática, na qual terá a oportunidade de aprender "como se faz", acompanhando um profissional experiente. Para nós, porém, o estágio não arremata a formação, visto que a experiência vivida nele não é capaz de proporcionar todas as dimensões do campo de atuação profissional.

Observação - participação - regência vem sendo o tripé básico da organização dos estágios, incluindo o que analisamos. Mas acreditamos que a forma linear com que essas fases têm sido exploradas não tem promovido espaço para diálogo e reflexão sobre as vivências dos estagiários em formação. Para nós, seria interessante trabalhar esse tripé de forma menos distanciada e mais cíclica, dando oportunidade para o aluno observar, participar e elaborar uma intervenção e posteriormente avaliar, compartilhar, promover momentos de reflexão e construção de conhecimento em grupo, ser orientado e mais outra vez voltar e vivenciar essas etapas. Assim, dúvidas, problemas, experiências significativas poderiam ser ouvidas, dando fala ao estagiário nesse processo importante da sua formação e não só no final do processo.

Acreditamos também que é preciso superar a comparação e adaptações ou customizações da EaD em relação ao modelo presencial e investir em investigações que apontem a EaD como uma modalidade diferente, diversa em possibilidades, mas que atualmente se encontra sendo explorada em condições inadequadas para a formação que se espera promover por meio dela. Portanto, o problema não está na modalidade, no uso de tecnologias digitais ou ainda na distância geográfica, mas sim na forma e nas condições em que ela vem sendo gerida e estruturada e nas políticas públicas para as quais ela tem sido usada.

\section{Agradecimentos}

À Fundação de Amparo à Pesquisa do Estado de Minas Gerais - FAPEMIG, pelo apoio financeiro em 2016.

\section{Referências Bibliográficas}

Álvares, C. C. O. T. (2015). A educação superior no Brasil e o Ensino: uma análise crítica do estágio supervisionado. Dissertação de mestrado. Universidade Estadual de Goiás.

Barreto, E. S. S. (2015). Políticas de formação docente para a educação básica no Brasil: embates contemporâneos. Revista Brasileira de Educação, 20(62), 679-701. http://dx.doi.org/10.1590/S141324782015206207 
Borba, M. C.; Malheiros, A. P. S.; Amaral, R. B. (2011). Educação a Distância online. $3^{a}$ ed. Belo Horizonte: Autêntica.

Brasil. Diretrizes e Normas Nacionais para a Oferta de Programas e Cursos de Educação Superior na Modalidade a Distância. Resolução CNE/CES 1/2016. Diário Oficial da União, Brasília, 14 de março de 2016, Seção 1, 23-24.

Dias-da-Silva, M. H. G. F. et al. (2008). A reestruturação das licenciaturas: alguns princípios, propostas e (pré) condições institucionais. Rev. Diálogo Educ., 8(23), 15-37. Disponível em: http://www.redalyc.org/ pdf/1891/189117303002.pdf

Diniz Pereira, J. E. (2007). Formação de professores, trabalho docente e suas repercussões na escola e na sala de aula. Educação \& Linguagem, 10(15), 82-98.

Felício, H. M. S.; Oliveira, R. A. (2008). A formação prática de professores no estágio curricular. Educar, Curitiba, 32, 215-232. http://www.scielo.br/pdf/er/n32/n32a15

Garnica, A. V. M. (2006) História oral e Educação Matemática. In: Marcelo de Carvalho Borba; Jussara de Loiola Araújo (Org.). Pesquisa qualitativa em Educação Matemática (2ª ed., p.79-100). Belo Horizonte: Autêntica.

Gatti, B. A. (2013-2014). A formação inicial de professores para a educação básica: as licenciaturas. Revista USP, 100, 33-46. http://dx.doi.org/10.11606/issn.2316-9036.v0i100p33-46.

Gatti, B. A.(2010). Formação de professores no Brasil: características e problemas. Educ. Soc., 31(113), 1.355-1.379. http://dx.doi.org/10.1590/S0101-73302010000400016

Lima, M.S.L.; Gonçalves, H. H. (2009). A práxis docente no desempenho das atividades do professor-formador. XI Congresso Nacional de Educação - EDUCERE, III Encontro Sul-Brasileiro de Psicopedagogia. Disponível em http://www.pucpr.br/eventos/educere/educere2009/anais/pdf/2935_1248.pdf

Lüdke, H. A. M. (2013). O lugar do estágio na formação de professores. Educação em Perspectiva, 4(1), 111 133. Disponível em http://www.seer.ufv.br/seer/educacaoemperspectiva/index.php/ppgeufv/article/ view/410/104

Lüdke, H. A. M. (2014). Estágio supervisionado: substantivo fictício? II Congresso Nacional de Formação de Professores e XII Congresso Estadual Paulista sobre Formação de Professores. Por uma revolução no campo da formação de professores. Disponível em http://www.geci.ibilce.unesp.br/logica de aplicacao/site/index_1.jsp?id_evento=31

Marcelo, C. (2009). Desenvolvimento profissional docente: passado e futuro, Sísifo Revista de Ciências da Educação, 8, 7-22.

Pimenta, S. G.; Lima, M. S. L. (2005-2006). Estágio e docência: diferentes concepções. Revista Poiésis, 3 (3-4), 5-24. https://doi.org/10.5216/rpp.v3i3\%20e\%204.10542

Quaranta, A. M.(2011). Formação de professores de Educação Física na modalidade de Educação a Distância: experiências docentes no estágio supervisionado. Dissertação de mestrado. Universidade Federal de Santa Catarina.

Reis, S. R. (2015). Estágio supervisionado no curso de Pedagogia a distância: aproximações e diferenças do ensino presencial. Tese de doutorado. Universidade Estadual Paulista.

Rela, E. et al. (2006). Supervisão e construção da avaliação em situações de estágio em cursos de licenciatura na modalidade a distância. Informática na Educação: teoria e prática, singularidades, coletivas e éticas, 1 (9), 57-72. Disponível em: http://www.lume.ufrgs.br/bitstream/handle/10183/23255/000629247.pdf?sequence $=1$ 